Check for updates

Cite this: RSC Adv., 2019, 9, 14531

\title{
Synthesis and characterization of polyaniline, polypyrrole and zero-valent iron-based materials for the adsorptive and oxidative removal of bisphenol-A from aqueous solution $\dagger$
}

\author{
Lerato Hlekelele, ${ }^{a}$ Nomvuyo E. Nomadolo, ${ }^{a}$ Katlego Z. Setshedi, ${ }^{a}$ \\ Lethula E. Mofokeng, ${ }^{\text {ab }}$ Avashnee Chetty ${ }^{a}$ and Vongani P. Chauke (D) *a
}

One pot synthesis of a polypyrrole, polyaniline and $\mathrm{Fe}^{0}$ nano-composite ( $\left.\mathrm{Fe}^{0}-\mathrm{PPY} / \mathrm{PANI}\right)$ was achieved by polymerizing aniline and pyrrole with $\mathrm{FeCl}_{3}$ followed by the reduction of $\mathrm{Fe}^{3+}$ to $\mathrm{Fe}^{0}$ with $\mathrm{NaBH}_{4}$. PPY/ PANI was synthesized the same way as $\mathrm{Fe}^{0}$-PPY/PANI, except that all the $\mathrm{FeCl}_{3}$ was removed by rinsing. The presence of $\mathrm{Fe}^{0}$ was demonstrated using several analytical techniques; this was shown in comparison to materials that are without $\mathrm{Fe}^{0}$. A series of materials were screened as both adsorbents and catalyst for the activation of $\mathrm{H}_{2} \mathrm{O}_{2}$ towards bisphenol A (BPA) removal in batch experiments. Polymers performed better than composites containing $\mathrm{Fe}^{0}$ at adsorption, whereas $\mathrm{Fe}^{0}$ based materials were better catalysts for the activation of $\mathrm{H}_{2} \mathrm{O}_{2}$. BPA samples were then spiked with other contaminants including sewage water to test the performance of the various adsorbents and Fenton catalysts. PPY/ PANI was found to be a better adsorbent than the rest, whereas $\mathrm{Fe}^{0}$-PPY/PANI was the best Fenton catalyst. The adsorption kinetics of BPA onto PPY/PANI was studied; it was found that the process was governed by the pseudo-second-order kinetic model. The adsorption isotherms revealed that the amount of BPA taken up by PPY/PANI increased with increasing temperature and was governed by the Langmuir adsorption isotherm. The mechanism in which $\mathrm{Fe}^{0}-\mathrm{PPY} / \mathrm{PANI}$ and $\mathrm{H}_{2} \mathrm{O}_{2}$ degraded BPA was studied, it was found that surface-bound hydroxyl radicals were responsible for the degradation of BPA. It was also shown that the degradation process included the formation of smaller compounds leading to the reduction of the total organic content by $57 \%$.

Received 5th March 2019

Accepted 26th April 2019

DOI: $10.1039 / c 9 r a 01666 j$

rsc.li/rsc-advances

\section{Introduction}

Bisphenol A, (BPA) (2,2-bis(4-hydroxyphenyl)propane), is one of the most frequently manufactured organic chemicals that is used in the production of polycarbonate plastics, epoxy resins and several other types of plastic product. ${ }^{1,2}$ The persistence of BPA in our environment, as well as its exposure to humans and animals, comes from its presence in baby feeding bottles, plastic containers, food cans and landfill leachates. ${ }^{3,4}$ BPA has been classified as an endocrine disrupting compound (EDC) as it has been shown to display hormone-like properties as it is able to disrupt the functioning of thyroid processes, and nervous and immune systems..$^{5-8}$ Furthermore, BPA exposure has been associated with poor sperm production and different kinds of cancer. ${ }^{9-11}$ Regrettably, BPA and

${ }^{a}$ Polymers and Composites, Materials Science and Manufacturing, Council for Scientific and Industrial Research, PO Box 395, 0001, Pretoria, South Africa. E-mail: VChauke@csir.co.za; Vonganic@yahoo.com

${ }^{b}$ Molecular Sciences Institute, School of Chemistry, University of the Witwatersrand (Wits), Private Bag X3, Johannesburg 2050, South Africa

$\dagger$ Electronic supplementary information (ESI) available. See DOI: 10.1039/c9ra01666j other EDC's (such as some hormones, pesticides, etc.) have been frequently detected in water and wastewater. ${ }^{12,13}$ This suggests that conventional drinking and wastewater treatment plants cannot completely remove all the EDCs. ${ }^{14}$

Various technologies have been developed and reported for the removal of EDCs, these include photocatalytic degradation, biological treatment, advanced oxidation processes (AOPs), and adsorption. ${ }^{15-17}$ Adsorption technology has received a lot of attention due to its simplicity, cost-effectiveness, and high efficiency. ${ }^{\mathbf{1 8 - 2 0}}$ Different adsorbents such as activated carbon, agricultural waste, polymer resin, organic clay, membranes, polymeric/inorganic hybrid composites, and zero-valent iron nanocomposites have been used for the removal of EDCs and various other contaminants. ${ }^{21-23}$ Organic polymeric materials such as polyaniline, polypyrrole, and composites of thereof have been shown to be potent adsorbents for the removal of pharmaceuticals, anions, organics, and cations. ${ }^{24-27}$ Furthermore, organic polymeric materials along with other types of carbon materials such as carbon nanotubes, graphene, and nitrogendoped carbon nanotubes can be used as supports for active nanomaterials for removing contaminants from water. ${ }^{28-30}$ 
On the other hand, zero-valent iron $\left(\mathrm{Fe}^{0}\right)$, is an environmentally friendly material which in the past few years has been exploited as a cheap catalyst in Fenton-like reactions. ${ }^{31,32}$ This is because $\mathrm{Fe}^{0}$ activates oxidants such as hydrogen peroxide $\left(\mathrm{H}_{2} \mathrm{O}_{2}\right)$ and persulphate $\left(\mathrm{S}_{2} \mathrm{O}_{8}{ }^{2-}\right)$ to form highly reactive (oxidizing) radicals such as hydroxyl $(\mathrm{HO})$, sulfate $\left(\mathrm{SO}_{4}{ }^{-}\right)$and superoxide $\left(\mathrm{O}_{2}{ }^{--}\right)$radical species which are known to be highly effective for degrading organic contaminants. ${ }^{31,32}$ Other materials which undergo AOPs and have been exploited for water remediation include titanium dioxide and its derivatives, ${ }^{33,34}$ Liu et al. also demonstrated the removal of over $75 \%$ of BPA within 12 hours using a zero valent aluminum-acid system. ${ }^{31}$ The high efficiencies of AOPs in the removal of BPA from water have motivated the synthesis of a dual nanocomposite, where it was postulated that polypyrrole-polyaniline would adsorb BPA and $\mathrm{Fe}^{0}$ would degrade BPA into less-toxic degradation products.

Therefore, the aim of this work was to synthesize and characterize materials consisting of polypropylene (PPY), polyaniline (PANI) and $\mathrm{Fe}^{0}$. These materials were tested as adsorbents and catalysts for the activation of $\mathrm{H}_{2} \mathrm{O}_{2}$ for Fenton-like reactions towards the removal of BPA. PPY and PANI are conducting polymers that have been used as mediums to root or house metal nanoparticles in nanocomposite synthesis. ${ }^{35}$ Moreover, PANI and PPY have nitrogen based functional groups that can assist in the removal of organic phenolic compounds through hydrogen bonding. ${ }^{36-38}$ In addition, immobilization of $\mathrm{Fe}^{0}$ nanoparticles onto polymer matrices has been demonstrated to be beneficial in reducing aggregation of $\mathrm{Fe}^{0}$ nanoparticles by Bhaumik et al., where they used PANI as a support material for $\mathrm{Fe}^{0}$ nanoparticles. ${ }^{39}$

\section{Experimental}

\section{Materials}

Pyrrole (PY, 99\%), anhydrous iron(III)chloride $\left(\mathrm{FeCl}_{3}\right)$, aniline (ANI, $\geq 99.5 \%$ ), sodium hydroxide $(\mathrm{NaOH}$ ) sodium borohydride $\left(\mathrm{NaBH}_{4}\right)$, bisphenol A (BPA, 99+\%), hydrochloric acid ( $\mathrm{HCl}$, $37 \%$ ), humic acid, potassium iodide (KI), hydrogen peroxide $\left(\mathrm{H}_{2} \mathrm{O}_{2}, 30 \mathrm{wt} \%\right.$ in $\left.\mathrm{H}_{2} \mathrm{O}\right)$ and sodium chloride $(\mathrm{NaCl})$ were all purchased from Sigma-Aldrich, SA. Argon gas (AR) was purchased from AFROX, South Africa. Phenol (99-100\% assay) was purchased from Parchem whereas methanol (99.8\% assays) was purchased from Protea Chemicals. Acetonitrile for HPLC, gradient grade (>99.9\%) was purchased from Merck. The water used in this work unless stated otherwise is pure water with a resistivity of $18.2 \mathrm{M} \Omega \mathrm{cm}$. Hypodermic polypropylene syringes $(5 \mathrm{ml})$ and $0.45 \mu \mathrm{m}$ cellulose acetate membrane syringe filters were purchased from Sigma-Aldrich SA. Sewage water was obtained from Marble Hall waste-water treatment plant in Limpopo province, South Africa.

\section{Materials synthesis}

Pyrrole ( $0.2 \mathrm{ml}-0.19 \mathrm{~g})$, aniline $(0.6 \mathrm{ml}-0.61 \mathrm{~g})$ and water $(80$ $\mathrm{ml}$ ) were added into a $250 \mathrm{ml}$ conical flask and stirred for 1 hour. $\mathrm{FeCl}_{3}(6 \mathrm{~g})$ was then added to the mixture and was stirred for a further 3 hours. Argon gas was then bubbled into the reaction mixture which contained residual $\mathrm{FeCl}_{3}$ and/or $\mathrm{FeCl}_{2}$ that served as a source of $\mathrm{Fe}$ to be reduced to nano $\mathrm{Fe}^{0}$. Freshly prepared $\mathrm{NaBH}_{4}(0.75 \mathrm{M})$ solution $(50 \mathrm{ml})$ was added dropwise to the reaction mixture to reduce oxidized Fe species to $\mathrm{Fe}^{0}$. The reaction mixture was then stirred for another $20 \mathrm{~min}$ to complete the reduction. After this, acetone was added to stop the polymerization reaction, followed by filtration to collect $\mathrm{Fe}^{0}$ PPY/PANI. The material was then washed with distilled water until the filtrate became colorless and washed with acetone to remove oligomers. The material was then dried in a vacuum oven at $90{ }^{\circ} \mathrm{C}$ for $24 \mathrm{~h}$. The theoretical composition of this material is $\mathrm{PPY}(13 \%)$ : PANI $(40 \%): \mathrm{Fe}^{0}(47 \%)$. In the case of $\mathrm{Fe}^{0}$ PPY and $\mathrm{Fe}^{0}$-PANI, the exact same procedure was used except for that only pyrrole $\left(0.8 \mathrm{ml}-0.77 \mathrm{~g}\right.$ and $\left.6 \mathrm{~g} \mathrm{FeCl}_{3}\right)$ was polymerized in the case of the former and the only aniline $(0.8 \mathrm{ml}-0.82 \mathrm{~g}$ and $6 \mathrm{~g} \mathrm{FeCl}_{3}$ ) was polymerized when making the latter. The theoretical composition of the two composites are PANI(55\%): (45\%) $\mathrm{Fe}^{0}$ and $\mathrm{PPY}(52):(48) \mathrm{Fe}^{0}$. When making materials that consisted of polymers only without $\mathrm{Fe}^{0}$, i.e. PPY, PANI, and PPY/ PANI, after polymerizing all of the $\mathrm{FeCl}_{3}$ was rinsed away with water when filtering. The theoretical composition of PPY/PANI is $\operatorname{PPY}(24 \%):(76 \%)$.

\section{Materials characterization}

The surface morphology of the samples was investigated by transmission electron microscopy (TEM, FEI Tecnai G2 Spirit electron microscope at $120 \mathrm{kV}$ ) and scanning electron microscopy (SEM, FEI NOVA nanolab $600 \mathrm{FIB} / \mathrm{SEM}$ ). For the powder Xray diffraction analysis, a PXRD, Bruker D2 PHASER diffractometer (Ni-filtered $\mathrm{Co}-\mathrm{K} \alpha$ radiation) was used. The surface area of the nanocomposite was determined by a Micromeritics Tristar II 3020 Surface Area and Porosity BET analyzer using nitrogen adsorption. Thermogravimetric analysis (TGA) was conducted in an air atmosphere on a TGA, PerkinElmer Pyris 1 TGA. The wettability studies were conducted on a KRUSS DSA 100.

The point of zero charge (pzc) was determined by the solid addition technique. ${ }^{40}$ Here, $5 \mathrm{mg}$ of the solid sample was dispersed in $25 \mathrm{ml}$ of $0.1 \mathrm{M} \mathrm{NaCl}$ and equilibrated at room temperature $\left(\mathrm{ca} .23^{\circ} \mathrm{C}\right)$ for 48 hours. The initial $\mathrm{pH}\left(\mathrm{pH}_{\mathrm{i}}\right)$ of the suspensions was adjusted using $0.05 \mathrm{M} \mathrm{HCl}$ and $0.05 \mathrm{M} \mathrm{NaOH}$. The final $\mathrm{pH}\left(\mathrm{pH}_{\mathrm{f}}\right)$ of the suspensions was measured after the 48 hours equilibration. The difference between $\mathrm{pH}_{\mathrm{f}}$ and $\mathrm{pH}_{\mathrm{i}}$ was plotted against $\mathrm{pH}$ and the $\mathrm{pzc}$, and the point where $\mathrm{pH}$ is equal to 0 , is the pzc of PPY/PANI.

\section{Removal experiments}

Batch experiments were conducted in 3 sets of experiments, (i) $\mathrm{pH}$ optimization, (ii) material screening experiments, and (iii) assessing the effect of other contaminants on the removal efficiencies of some of the materials synthesized. BPA solutions were prepared in $5 \%$ acetonitrile in water. In $\mathrm{pH}$ optimization experiments, $50 \mathrm{ml}$ of $50 \mathrm{ppm}$ solution of BPA was transferred into a plastic bottle. To these solutions, $25 \mathrm{mg}$ of the materials were added, closed and agitated at $200 \mathrm{rpm}$ in a thermostatic 
shaker for $24 \mathrm{~h}$. The $\mathrm{pH}$ of the solutions was varied using $\mathrm{NaOH}$ or HCl. Also, in Fenton reactions, $15 \mathrm{ppm}$ of $\mathrm{H}_{2} \mathrm{O}_{2}$ was added simultaneously with the catalyst to initiate the reaction. In experiments where the effect of other contaminants was studied, $0.12 \mathrm{M}$ of $\mathrm{NaCl}$, or $10 \mathrm{ppm}$ phenol or $2 \mathrm{ppm}$ humic acid was added to the relevant BPA solutions.

Kinetics experiments were also performed where, typically, $200 \mathrm{ml}$ BPA solution at a $\mathrm{pH} 6$ for adsorption experiments and pH 3 for Fenton-like reactions was transferred into a $500 \mathrm{ml}$ glass beaker. To this solution, $100 \mathrm{mg}$ of the adsorbent or Fenton catalyst was added to initiate the reaction and agitated using an overhead stirred batch reactor stirring at $200 \mathrm{rpm}$. Also, 15 ppm of $\mathrm{H}_{2} \mathrm{O}_{2}$ was added in Fenton reactions. Additionally, in scavenging experiments, $5 \mathrm{mM}$ KI or $350 \mathrm{mM}$ methanol was added to the BPA solutions. In experiments where the effect of sewage-water was investigated, $25 \%$ of filtered sewage water was added to the BPA solutions. In all of these kinetics experiments, $1 \mathrm{ml}$ aliquots were sampled using a syringe at predetermined intervals and filtered using a syringe filter.

The samples in all of these experiments were analyzed using high-performance liquid chromatography (Shimadzu HPLC, SPD-M20A, and Prominence with a UV/VIS Photodiode Array Detector). The analyst was eluted using a gradient solvent system consisting of water and acetonitrile. The gradient was as follows: the gradient began with $30 \%$ acetonitrile for $6 \mathrm{~min}$, followed by the increase of acetonitrile to $90 \%$ over 2 min and kept like this for $1 \mathrm{~min}$. The concentration of acetonitrile was then reduced back to $30 \%$ in $8 \mathrm{~min}$ and kept constant for $3 \mathrm{~min}$. The gradient flow rate was $0.2 \mathrm{ml} \mathrm{min}^{-1}$ using a Phenomenex LUNA $5 \mu \mathrm{m}$ C18 reverse phase column $(150 \times 4.60 \mathrm{~mm})$. The BPA concentration was measured at $225 \mathrm{~nm}$. Total organic content (TOC) measurements were done using a TOC analyzer (Tekmar Dohrmann Apollo 9000) relying on $\mathrm{CO}_{2}$ for quantification. $\mathbf{. 4 , 4 1}^{\mathbf{4}}$

In order to identify the degradation products, having performed kinetics experiments for Fenton-like reactions, the remaining solution was filtered to remove the catalyst particles. The liquid was then freeze-dried using a Telstar (LyoAlfa10) freeze drier. The dry samples were then dissolved in $10 \mathrm{ml}$ acetonitrile and analyzed on an LC/MS/MS system. The chromatography was performed using the same column, solvent gradient system, and flow rate as described above and the intermediates were identified using mass-spectrometry (3200 Q TRAP LC/MS/MS). The MS was operated in the negative ion mode at an $m / z$ range of $50-300$.

\section{Results and discussion}

\section{Materials characterization}

The PXRD analysis was conducted on the materials in order to differentiate the diffraction properties of PPY, PANI, PPY/PANI and $\mathrm{Fe}^{0}$-PPY/PANI (Fig. 1). A broad peak was observed on the PXRD pattern of PPY at a $2 \theta$ value of $31^{\circ}$. This peak was assigned as a characteristic peak for PPY that resulted from the $\pi-\pi$ interactions of partial PPY chains, comparable to those that occur in the case of aromatic groups. ${ }^{\mathbf{4 2 , 4 3}}$ The broadness of the

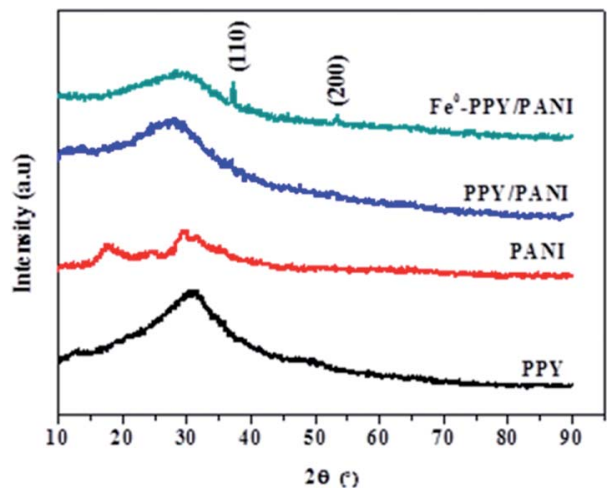

Fig. 1 The PXRD patterns of the various materials.

peak showed the amorphous nature of the polymer. In the case of PANI, several peaks were observed at $2 \theta$ values of 12.3, 18.2, 25.3, 30.1, 32.3 and 35.3 and were assigned as (001), (011), (020), (200), (121) and (022) reflections of the emeraldine salt form of PANI. ${ }^{44}$ The PXRD patterns of PPY/PANI and $\mathrm{Fe}^{0}$-PPY/PANI were observed to have been similar to that of PPY (without PANI characteristic peaks) except for that the peaks were broader and were centered at lower $2 \theta$ values $\left(2 \theta=31.5^{\circ}\right.$ for PPY, $29.8^{\circ}$ for PPY/PANI and $27.8^{\circ}$ for $\mathrm{Fe}^{0}$-PPY/PANI). The broadness of these peaks suggested polymerizing the two polymers simultaneously compromised their crystallinity thus yielding a material that was more amorphous than the separate polymers. Furthermore, two low intensity and narrow peaks were observed on the PXRD pattern of $\mathrm{Fe}^{0}$-PPY/PANI, at $2 \theta$ values of 37.3 and 53.7 and were attributed to the presence of $\mathrm{Fe}^{0}$, similar peaks were observed by Hwang et al. and were attributed to nanoscale $\mathrm{Fe}^{0} .^{45}$ Important information was deduced from PXRD analysis: (i) it was established that PANI and PPY were successfully polymerized together (to form PPY/PANI composite), and (ii) $\mathrm{Fe}^{3+}$ (used as an initiator for the polymerization of pyrrole and aniline) was reduced to $\mathrm{Fe}^{0}$ in the presence of the polymer composite to form $\mathrm{Fe}^{0}$-PPY/PANI.

TEM and SEM imaging analyses were conducted on the samples in order to study their morphological characteristics. The morphology of $\mathrm{Fe}^{0}$-PANI was observed to be fibrous and intertwined (Fig. 2a and c), similar to that which was observed by Rahy et $a l .{ }^{46}$ On the other hand, the morphology of $\mathrm{Fe}^{0}$-PPY was observed to be spheres that were linked into a chain like morphology, Fig. 2b and c. Similar morphological properties were observed by Chougule et al. ${ }^{47}$ Dark spots were observed on the TEM images of PANI and PPY; this was because of the $\mathrm{Fe}^{0}$ nanoparticles.

The TEM image of the $\mathrm{Fe}^{0}$-PPY/PANI composite revealed that the material consisted of the morphological characteristics which were observed for $\mathrm{Fe}^{0}$-PANI and $\mathrm{Fe}^{0}$-PPY separately (Fig. 2c). Here, also, the $\mathrm{Fe}^{0}$ nanoparticles were identified as the particles (dark spots) embedded in the polymeric material on the TEM image (Fig. 2c). It was possible to differentiate between PANI/PPY and $\mathrm{Fe}^{0}$ by contrast because $\mathrm{Fe}^{0}$ nanoparticles are significantly heavier than PPY or PANI and as such the interactions with the beam of electrons differed. The particle size distribution of the $\mathrm{Fe}^{0}$ nanoparticles was measured to have 

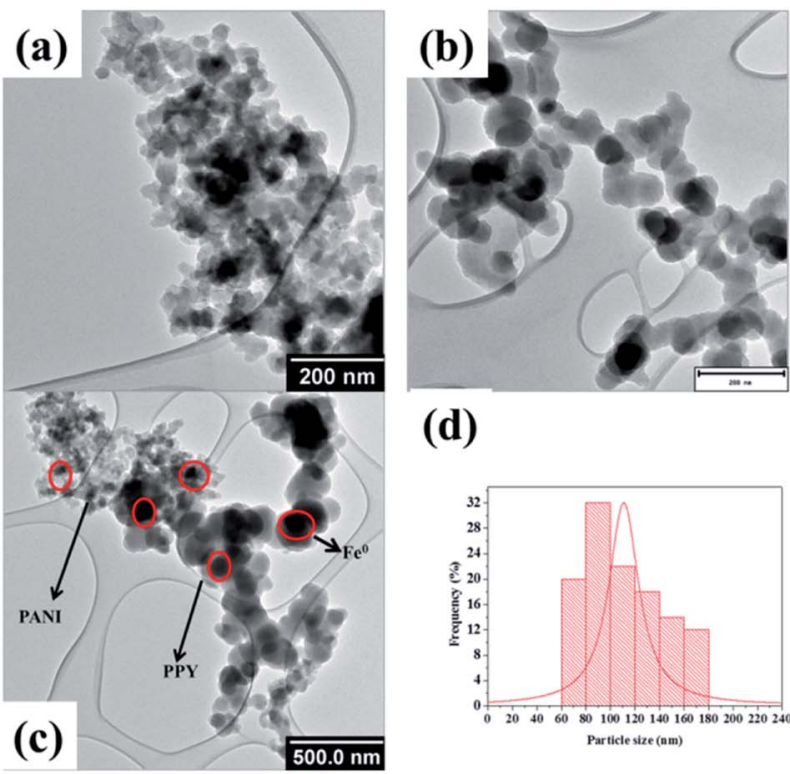

(d)
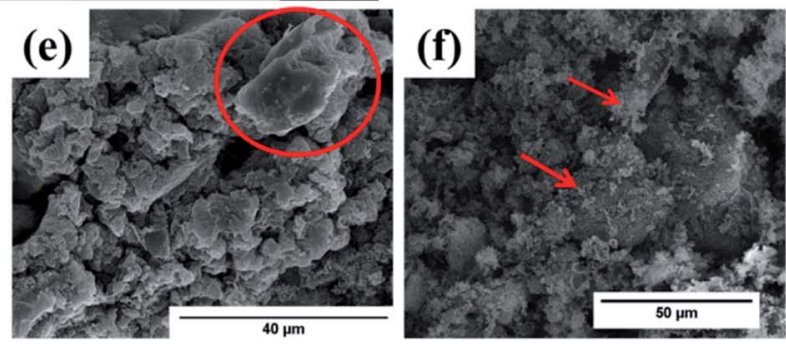

Fig. 2 TEM images of (a) $\mathrm{Fe}^{0}-\mathrm{PANI}$, (b) $\mathrm{Fe}^{0}-\mathrm{PPY}$, (c) $\mathrm{Fe}^{0}-\mathrm{PPY} / \mathrm{PANI}$ (d) particle size distribution of $\mathrm{Fe}^{0}$ nanoparticles in $\mathrm{Fe}^{0}-\mathrm{PPY} / \mathrm{PANI}$ and SEM image of (e) PPY/PANI and (f) $\mathrm{Fe}^{0}$-PPY/PANI.

been between 60 and $180 \mathrm{~nm}$ at an average of $110 \mathrm{~nm}$ (Fig. 2d). It was observed on the SEM image of PPY/PANI that the surface of the material is smooth (Fig. 2e). The circled area on the SEM image (Fig. 2e) better shows the smoothness of PPY/PANI. This is also shown in Fig. S1a. $\dagger$ On the other hand, the morphology of $\mathrm{Fe}^{0}$-PPY/PANI is characterized by a harsher surface caused by the $\mathrm{Fe}^{0}$ nanoparticles loaded on the surface of PPY/PANI (Fig. $2 \mathrm{f}$ and S1b†). The EDS spectrum of PPY/PANI showed that the material consisted of only carbon (nitrogen atoms were not picked because of their low relative abundance) (Fig. S1c†) whereas Fe was detected and observed on the EDS spectrum $\mathrm{Fe}^{0}$-PPY/PANI (Fig. S1d $\dagger$ ). Furthermore, $\mathrm{Fe}^{0}$-PPY/PANI was mapped using EDS to study the dispersion of the $\mathrm{Fe}^{0}$ nanoparticles on the surface of PPY/PANI (Fig. S2a and $b_{\dagger} \dagger$ ). Here, it was observed that the $\mathrm{Fe}^{0}$ nanoparticles are well distributed on the surface of PPY/PANI. No evidence of agglomeration was observed.

TGA measurements of PPY/PANI (Fig. 3a) and $\mathrm{Fe}^{0}$-PPY/PANI (Fig. 3b) were performed in order to study the thermal properties of the materials and to estimate the amount of noncombustible iron species in the materials. The thermogram of PPY/PANI started decreasing from the onset and stopped decreasing at $600{ }^{\circ} \mathrm{C}$ at which point, over $90 \%$ of the material had combusted. The residual non-combustible material which was less than $10 \%$ of the material was attributed to $\mathrm{Fe}$ and $\mathrm{Cl}$ species that remained when the material was rinsed. In the case (a)
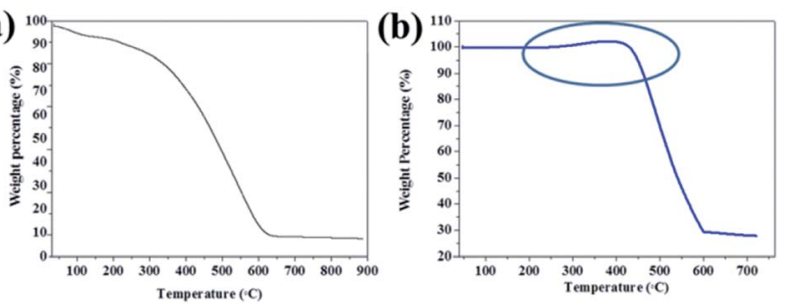

Fig. 3 Thermogram of (a) PPY/PANI and (b) Fe $\mathrm{Fe}^{0}$ PPY/PANI.

of $\mathrm{Fe}^{0}$-PPY/PANI, it was observed that $68 \%$ of the material was carbonaceous material (polymer) as it was combusted at temperatures below $600{ }^{\circ} \mathrm{C}$ (Fig. $3 \mathrm{~b}$ ). The remaining residue which accounted for $32 \mathrm{wt} \%$ was attributed to $\mathrm{Fe}^{0}$ as it was the only other material in the composite except for the polymer materials as it was shown by PXRD. The mass of the sample was observed to have increased at temperatures between 200 and $450{ }^{\circ} \mathrm{C}$, indicating that the material was oxidizing further proving that iron in the material was in its zero valent state.

The BET surface area of PPY/PANI was found to be $27.5 \mathrm{~m}^{2}$ $\mathrm{g}^{-1}$ whereas that of $\mathrm{Fe}^{0}$-PPY/PANI was $20.1 \mathrm{~m}^{2} \mathrm{~g}^{-1}$. The reduction in surface area was attributed to that the smaller $\mathrm{Fe}^{0}$ particles blocked the polymer substrate pores thus reducing the surface area.

\section{Removal experiments}

pH optimization. The first experiment performed in this work was to investigate the optimum $\mathrm{pH}$ that the most basic adsorbent (PPY) and most basic Fenton catalyst $\left(\mathrm{Fe}^{0}\right)$ can remove BPA. The influence of solution $\mathrm{pH}$ on BPA adsorption onto PPY/PANI was investigated at a pH range $2.0-10$ and data is shown in Fig. 4a. Solution pH plays a significant role in adsorption processes as it governs the protonation or deprotonation of target compounds in the aqueous phase and the surface charge density of the adsorbent. ${ }^{37,48}$ Meanwhile, Fig. 4 shows that the adsorption of BPA onto PPY was the highest when the $\mathrm{pH}$ of the solution was low i.e. 2.0-6.0, with slight variations. A linear decrease in BPA adsorption was observed as the solution $\mathrm{pH}$ was increased from $\mathrm{pH}$ 6.0-10.0. This observation was attributable to the postulation that, in alkaline conditions, a negative charge is created on the PPY surface, and correspondingly, the BPA hydroxyl groups become deprotonated to form monoanions $\left(\mathrm{HBPA}^{-}\right)$and dianions $\left(\mathrm{BPA}^{2-}\right)$. This
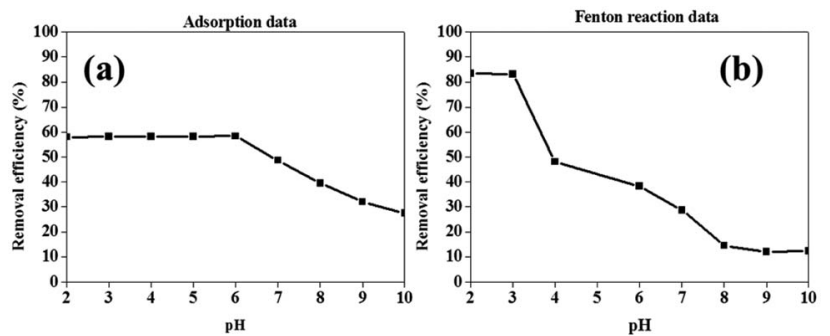

Fig. 4 Effect of pH on the (a) adsorption of BPA using PPY and (b) Fenton degradation of BPA using $\mathrm{Fe}^{\mathrm{O}}$. Experimental conditions: $50 \mathrm{ml}$ of 50 ppm BPA, $25 \mathrm{mg}$ of catalyst or adsorbent and $15 \mathrm{ppm} \mathrm{H}_{2} \mathrm{O}_{2}$ for only Fenton reactions. 
resulted in electrostatic repulsion between the PPY surface and BPA ions. Indeed, the same phenomenon was observed by $\mathrm{Li}$ et al. except for in their work, the repulsion was observed between BPA and the negatively charged surface of $\mathrm{CNTs} / \mathrm{Fe}_{3} \mathrm{O}_{4}$ at $\mathrm{pH} 10.4 .^{49}$ Therefore, subsequent adsorption experiments were conducted at $\mathrm{pH} 6$, unless stated otherwise.

In the case of the removal of BPA by Fenton reaction using $\mathrm{Fe}^{0}$ and $\mathrm{H}_{2} \mathrm{O}_{2}$, it was observed that the removal of BPA was at its highest at $\mathrm{pH}$ values below 3 (Fig. 4b). At $\mathrm{pH}$ values higher than 3 , it was observed that the removal efficiency decreased with increasing $\mathrm{pH}$ values. This was attributed to two factors, the direct participation of $\mathrm{H}^{+}$in the degradation reaction and mass transport limitations as a result of a formation of hydroxide precipitation on the surface of the material at higher $\mathrm{pH}$ values. $^{50,51}$ Consequently, succeeding Fenton reactions were conducted at $\mathrm{pH} 2$, unless specified otherwise.

Material performance as adsorbents and catalysts. Here it was observed that the materials generally performed better in Fenton reactions than they did in adsorption experiments (Fig. 5). This is because it is possible to activate $\mathrm{H}_{2} \mathrm{O}_{2}$ to form radical species capable of oxidizing organic contaminants. ${ }^{52,53}$ This is particularly common when $\mathrm{H}_{2} \mathrm{O}_{2}$ is used with $\mathrm{Fe}^{0}$ but it has also been shown that carbonaceous materials are capable of activating $\mathrm{H}_{2} \mathrm{O}_{2} \cdot{ }^{54}$ It was also observed that PPY/PANI was the best adsorbent, followed by PPY and $\mathrm{Fe}^{0}$-PPY/PANI with every other material removing less than $50 \%$ of BPA (Fig. $5 \mathrm{a}$ ). On the other hand, it was seen that $\mathrm{Fe}^{0}$ followed by $\mathrm{Fe}^{0}$-PPY/PANI and $\mathrm{Fe}^{0}$-PPY were the most active materials for the activation of $\mathrm{H}_{2} \mathrm{O}_{2}$ for the degradation of BPA (Fig. 5b).

Effect of other contaminants on the removal of BPA. The next study that was performed was to study the influence of other contaminants on the removal efficiency of BPA by adsorption or through oxidation via the activation of $\mathrm{H}_{2} \mathrm{O}_{2}$. The experiments were conducted using materials that were observed to be highly effective for the removal of BPA in the screening experiments, i.e. PPY, PPY/PANI and $\mathrm{Fe}^{0}$-PPY in the case of adsorption and $\mathrm{Fe}^{0}, \mathrm{Fe}^{0}$-PPY and $\mathrm{Fe}^{0}$-PPY/PANI in Fenton reactions. Here it was also observed that more BPA was removed by Fenton reaction than by adsorption (Fig. 6). Meanwhile, the best performing adsorbent was generally PPY/PANI followed by PPY and $\mathrm{Fe}^{\mathrm{O}}$-PPY was the least potent adsorbent (Fig. 6a). Indeed, this was true for all 3 experiments where different contaminants were added to the test solution. Nevertheless, the removal
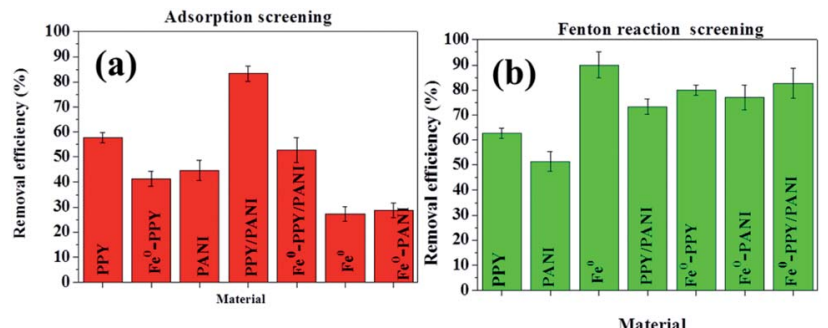

Fig. 5 Removal efficiencies of BPA using the various materials by (a) adsorption and (b) Fenton reaction. Experimental conditions: $50 \mathrm{ml}$ of 50 ppm BPA, 25 mg of catalyst or adsorbent and $15 \mathrm{ppm} \mathrm{H}_{2} \mathrm{O}_{2}$ for only Fenton reactions.
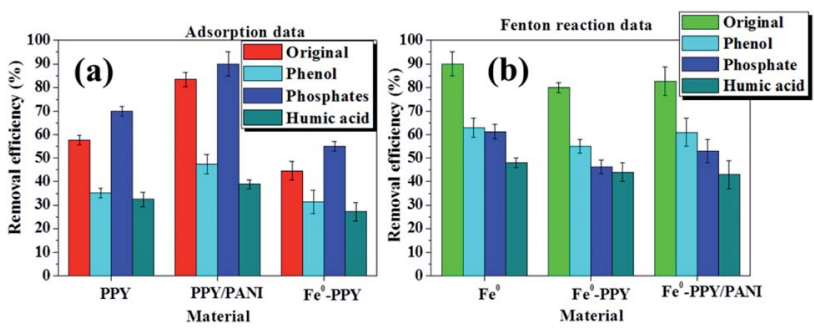

Fig. 6 Removal efficiencies of bisphenol-A in the presence of other contaminants using the various materials by (a) adsorption and (b) Fenton reaction. Experimental conditions: $50 \mathrm{ml}$ of $50 \mathrm{ppm}$ BPA, $25 \mathrm{mg}$ of catalyst or adsorbent and $15 \mathrm{ppm} \mathrm{H}_{2} \mathrm{O}_{2}$ for only Fenton reactions.

efficiencies of the adsorbents in the presence of phenol and humic acid were considerably lower than the efficiencies that were observed in the absence of other contaminants (see Fig. 5a and 6a). This was more pronounced in the case of samples spiked with humic acid where it was observed that the least amount of BPA was adsorbed followed by samples spiked with phenol. This was not the case with BPA samples spiked with $\mathrm{NaCl}$. Here an increase in BPA uptake was observed indicating that the presence of the salt promotes the uptake of BPA.

The attenuation of adsorption of various kinds of organic contaminants on carbon-based adsorbents as a result of the presence of humic acid has been reported in other publications. ${ }^{55-57}$ Jiyong et al. observed this when adsorbing 17-ethinyl estradiol or BPA on single-walled carbon nanotubes. ${ }^{48}$ They contributed their observations to two possible reasons: (i) the two model contaminants were in competition with humic acid for adsorption sites and (ii) the humic acid blocked the pores on the adsorbents. These reasons also explain the adsorption attenuation of BPA on the materials reported here in the presence of humic acid.

The adsorption efficiencies of BPA in the presence of phenol using the various materials were the second lowest observed in our experiments (Fig. 6a). This was because phenol is a smaller organic compound compared to BPPA and it has similar structural properties as BPA except it looks like half of BPA. This indicates that the two compounds competed for the adsorption sites on the surface of the adsorbent materials and were adsorbed by the same mechanism thus reducing the efficiency at which BPA was adsorbed.

In the case of samples spiked with $\mathrm{NaCl}$, the adsorption of BPA using the various materials increased. This experiment was conducted to investigate the influence that electrolytes have on the materials synthesized. This observation was explained by the screening effect phenomenon. This occurred because the presence of a relatively high concentration of $\mathrm{NaCl}$ affected the surface charge of the aromatic polymeric adsorbents to favor the $\pi-\pi$ dispersion interactions. ${ }^{58,59}$ This then consequently increased the adsorption of BPA onto the adsorbents.

The effect that phenol, humic acid, and $\mathrm{NaCl}$ had on the removal of BPA through the activation of $\mathrm{H}_{2} \mathrm{O}_{2}$ using the various catalysts was also investigated and the results are plotted in Fig. $6 \mathrm{~b}$. Here it was observed that the removal efficiencies of the various materials were reduced significantly by the various 
contaminants, with $\mathrm{Fe}^{0}$ showing the best performance followed by $\mathrm{Fe}^{0}$-PPY/PANI. The activation of $\mathrm{H}_{2} \mathrm{O}_{2}$ for the removal of contaminants usually follows the radical formation route; this is crucial to why the presence of other contaminants reduced the removal of BPA. Phenol competed directly with BPA for radicals thus the attenuation of the removal efficiency. In the case of humic acid, it is possible that it may have combined with the carbon-based catalyst to form complexes that hindered the usual activation pathways. ${ }^{\mathbf{6 0}}$ It was postulated that the decrease in performance as a result of the presence of chlorides was due to that the chlorides quenched the radicals and formed lessoxidative species as was reported for iodine atoms. ${ }^{61}$

Effect of sewage water on the removal of BPA. Two best performing adsorbents (PPY/PANI and PPY, see Fig. 6a) and catalysts $\left(\mathrm{Fe}^{0}\right.$ and $\mathrm{Fe}^{0}$-PPY/PANI, see Fig. $\left.6 \mathrm{~b}\right)$ were tested if they would still be able to efficiently remove BPA in the presence of actual sewage water and reduce the overall total organic content (TOC) in the samples. It was observed that the performance of the materials as adsorbents (Fig. 7a) and catalysts for the activation of $\mathrm{H}_{2} \mathrm{O}_{2}$ (Fig. 7b) were low. This indicated that the extra contaminants in the sewage water hampered the performance of the material probably because of competition with other contaminants.

In order to investigate this claim, several other experiments were conducted to determine the effect of different parameters on the removal of BPA and TOC attenuation. The parameters investigated were the adsorbent/catalyst dosage, $\mathrm{H}_{2} \mathrm{O}_{2}$ concentration (only in Fenton reactions) and the amount of sewage water. These experiments were conducted using the better performing adsorbent (PPY/PANI) and catalyst ( $\mathrm{Fe}^{0}$-PPY/PANI).

Data obtained when investigating the effect of sewage water concentration on the ability of PPY/PANI and $\mathrm{Fe}^{0}$-PPY/PANI to remove BPA as an adsorbent and catalyst respectively are shown in Fig. S3a and b. $\dagger$ Here it was observed that in both adsorption and catalytic experiments, the amount of BPA removed decreased with increasing concentration of sewage water. This demonstrates that the constituents of the sewage water competed with BPA. A similar conclusion that the elements of sewage water competed with BPA was reached having observed how the mass of adsorbent (PPY/PANI) and Fenton catalyst $\left(\mathrm{Fe}^{0}\right.$ PPY/PANI) affected the BPA uptake. Here, it was observed that the amount of BPA uptake increased with an increasing amount


Fig. 7 Removal efficiencies of bisphenol-A and TOC using various materials by (a) adsorption and (b) Fenton reaction. Experimental conditions: $200 \mathrm{ml}$ of 50 ppm BPA, pH 6 for adsorption experiments and $\mathrm{pH} 3$ for Fenton reactions, $100 \mathrm{mg}$ of adsorbent or Fenton catalyst and $25 \%$ of sewage-water. of adsorbent and Fenton catalyst (Fig. S4†). TOC measurements were also recorded as a function of the mass of adsorbent and Fenton catalyst. It was observed that the total organic content also decreased with increasing mass of materials, achieving more than $50 \%$ removal efficiency in both adsorption and Fenton experiments (Fig. S4 $\dagger$ ). This showed that with the right dosage, the materials can be applicable in real life samples.

The effect that the concentration of $\mathrm{H}_{2} \mathrm{O}_{2}$ has on the removal efficiency of BPA and total organic content by Fenton reaction using $\mathrm{Fe}^{0}$-PPY/PANI was also investigated (Fig. S5 $\dagger$ ). These experiments were conducted because $\mathrm{H}_{2} \mathrm{O}_{2}$ plays an important role in Fenton like experiments. Here, it was observed that BPA removal efficiency increased with increasing $\mathrm{H}_{2} \mathrm{O}_{2}$ from 2 to $20 \mathrm{mM}$. The removal efficiency decreased slightly when the concentration of $\mathrm{H}_{2} \mathrm{O}_{2}$ was above $20 \mathrm{mM}$. The scavenging effect brought upon by the surplus amount of $\mathrm{H}_{2} \mathrm{O}_{2}$ possibly caused a slight decrease in BPA uptake (see eqn (S1) and (S2) $\dagger$ ). Nevertheless, the BPA and TOC uptakes reached 85 and 65\% respectively, showing that the matter in the sewage water used was in competition with BPA and that the materials have a potential of being used in real life samples.

Adsorption kinetics of BPA onto PPY/PANI. The reaction kinetics of BPA adsorption onto PPY/PANI was evaluated to determine the residence time required for equilibrium attainment as a function of initial BPA concentration (Fig. 8). The adsorption process was characterized by a rapid BPA uptake which was observed in the first $10 \mathrm{~min}$, which subsequently slowed down as the reaction approached equilibrium. Moreover, the amount of BPA adsorbed per unit mass of PPY/PANI increased with increasing initial BPA concentration. Increasing the BPA concentration increased the concentration gradient, and as a result, provided a driving force to overcome mass transfer resistance between the aqueous and solid phases. ${ }^{37,62,63}$ The equilibrium was attained at different times for the various BPA concentrations, where it was found that the time required to reach the adsorption equilibrium increased with

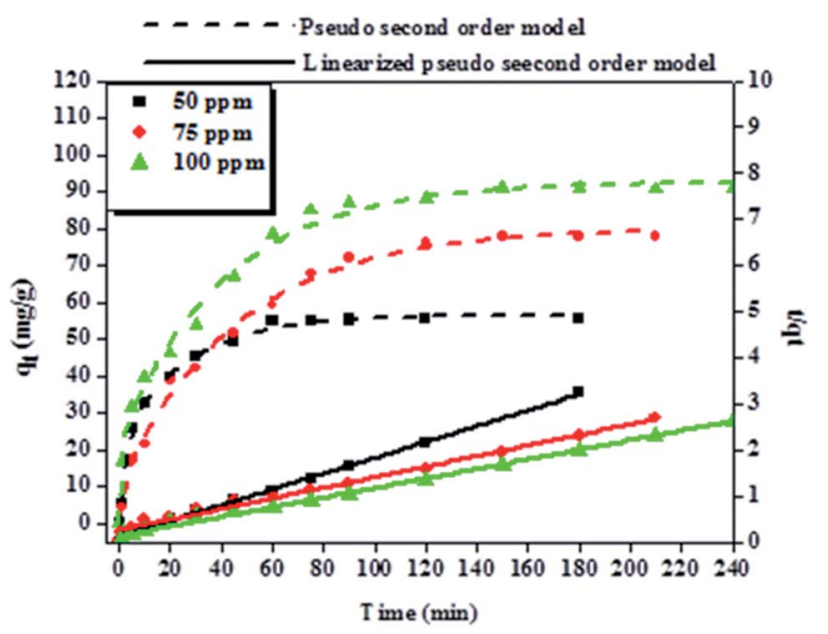

Fig. 8 Adsorption kinetics and the pseudo-second-order kinetic plot of BPA adsorption onto $50 \mathrm{mg}$ of PPY/PANI. Experimental conditions: $200 \mathrm{ml}$ of various concentrations of BPA $(50,75$ and $100 \mathrm{ppm})$ at $\mathrm{pH}$ 6.0 and at $23^{\circ} \mathrm{C}$. 
increasing BPA concentration. Further analysis of the graph (Fig. 8) revealed that the $q_{\mathrm{e}}$ 's were approximately 55, 72 and $88 \mathrm{ppm}$ for the 50, 75 and 100 ppm BPA solutions, respectively.

To explore the adsorption mechanism and reaction rates of BPA adsorption onto PPY/PANI, the kinetics data were subjected to the linearized forms of the Lagergren pseudo-first order (eqn (1)) and Ho pseudo-second order (eqn (2)) kinetic models given by,

$$
\begin{gathered}
\ln \left(q_{\mathrm{e}}-q_{t}\right)=\ln q_{\mathrm{e}}-k t \\
\frac{t}{q_{t}}=\frac{1}{k_{2} q_{\mathrm{e}}^{2}}+\frac{t}{q_{\mathrm{e}}}
\end{gathered}
$$

where $k_{1}\left(\min ^{-1}\right)$ and $k_{2}\left(\mathrm{~g} \mathrm{mg}^{-1} \mathrm{~min}^{-1}\right)$ are the pseudo-firstorder and pseudo-second-order rate constants, respectively, $q_{t}$ is the amount of BPA adsorbed at any time $\left(\mathrm{mg} \mathrm{g}^{-1}\right)$ and $q_{\mathrm{e}}$ is equilibrium adsorption capacity $\left(\mathrm{mg} \mathrm{g}^{-1}\right)$. The linear plots of $\ln \left(q_{\mathrm{e}}-q_{t}\right)$ versus $t$ and $t / q_{t}$ versus $t$ (Fig. 8) were obtained and their respective parameters were calculated and are shown in Table 1. Relatively higher linear regression coefficients $\left(R^{2}>\right.$ $0.994)$ were obtained for the pseudo-second-order model as opposed to the regression coefficients obtained for the pseudofirst-order model (Table 1). This observation along with the closeness of the equilibrium adsorption capacity obtained experimentally and by calculation (refer to Fig. 8 and Table 1), showed that the adsorption of BPA onto PPY/PANI followed the pseudo-second-order kinetic model.

\section{Diffusion processes}

Information about the adsorption mechanism provides valuable insights on the overall rate of adsorption, where a ratelimiting step of the adsorption of BPA onto PPY/PANI can be determined. This is useful for the design and optimization of adsorption system conditions. ${ }^{64}$ Adsorption dynamics can be described in four consecutive steps which are as follows: (i) film or surface diffusion where the adsorbate is transported from the bulk solution to the external surface of adsorbent, (ii) interparticle diffusion, (iii) intraparticle or pore diffusion, where the adsorbate molecules move into the interior of adsorbent particles, and (iv) chemical reaction on the sorbent surface. ${ }^{64}$ The first step is controlled by the stirring rate in the flask and the surface chemical reaction step is usually fast. Thus, the two steps cannot be the rate limiting steps and we can assume that one of the two or both the diffusion processes (step ii and iii) are the limiting steps and consequently. To describe the interparticle diffusion, the transfer of BPA onto a solid phase can be modeled by relation eqn (3).

$$
-\frac{\mathrm{d} C_{t}}{\mathrm{~d} t}=k_{V}^{\mathrm{a}}\left(C_{t}-C_{\mathrm{e}}\right)
$$

where $k\left(\mathrm{~m} \mathrm{~min}^{-1}\right)$ is the kinetic constant, $V\left(\mathrm{~m}^{3}\right)$ is the initial volume of the solution and $\mathrm{a}$ is the interfacial area between the liquid and the solid phases $\left(\mathrm{m}^{2}\right) . C_{t}$ and $C_{\mathrm{e}}$ are the solution concentrations at any given time and at equilibrium, respectively. The integrated form of this relation is given by eqn (4).

$$
\ln \left(\frac{C_{\mathrm{o}}-C_{\mathrm{e}}}{C_{t}-C_{\mathrm{e}}}\right)=k_{V}^{\mathrm{a}}=k^{\prime} t
$$

where $k^{\prime}$ is the global kinetic constant $\left(\min ^{-1}\right)$ and $C_{\mathrm{o}}$ is the initial concentration of the adsorbate. The linear plots that describe the diffusion model are fitted below (Fig. 9a). It was observed from the curves that the rate limiting step for the mass transfer of BPA is the external (interparticle) diffusion. This is

Table 1 Adsorption kinetics models for BPA adsorption onto PPY/PANI

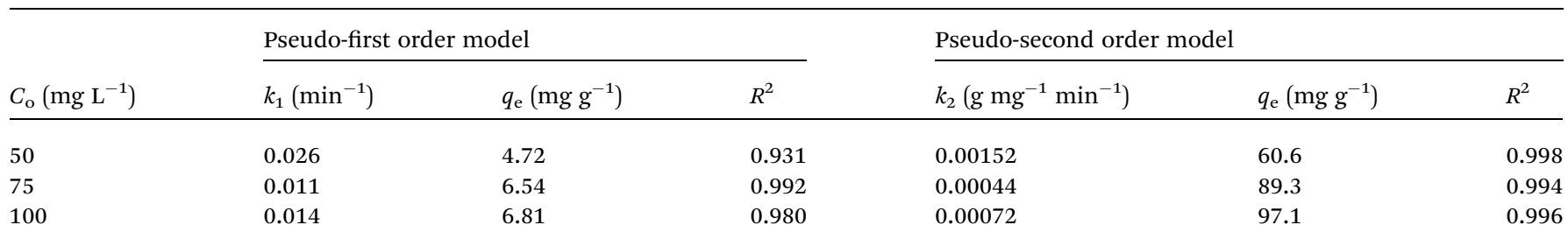
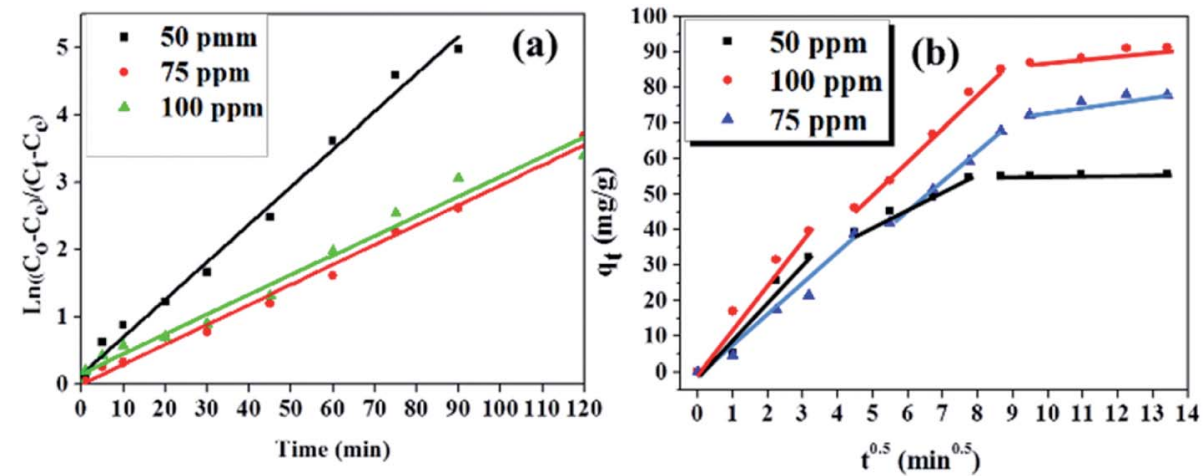

Fig. 9 Diffusion models showing (a) interparticle and (b) intraparticle. Experiments conditions: 200 ml of various concentrations of BPA (50, 75 and $100 \mathrm{ppm}$ ) at $\mathrm{pH} 6.0$ and at $23^{\circ} \mathrm{C}$ adsorbed onto $50 \mathrm{mg}$ of PPY/PANI. 
because the relationship was linear $\left(R^{2} \approx 0.99\right)$ and the intercepts of each of the linear lines were close to zero (Table 2).

The intraparticle diffusion can also be a significant step in this adsorption diffusion process. The Weber-Morris relation (eqn (5)) is used to define the intraparticle diffusion mechanism. This is denoted by the relationship between the timedependent adsorption capacity $\left(q_{t}\right)$ and the $t^{0.5}$ shown in eqn (5).

$$
q_{t}=K_{\mathrm{P}} t^{0.5}+C
$$

where $K_{\mathrm{p}}$ is the intraparticle diffusion rate constant $\left(\mathrm{mg} \mathrm{g}^{-1}\right.$ $\min ^{-0.5}$ ) and $C$ is the intercept $\left(\mathrm{mg} \mathrm{g}^{-1}\right)$. It was observed from investigating Fig. 9b that the plots of $q_{t}$ versus $t^{0.5}$ were all linear suggesting that intraparticle diffusion is or one of the ratelimiting steps in the adsorption of BPA onto PPY/PANI. It was also observed that the linear plots passed through the origin further indicating that intraparticle diffusion is or one of the rate-limiting steps. It was also observed that the plots of $q_{t}$ versus $t^{0.5}$ were multilinear; this meant that then two or more steps govern the adsorption process. ${ }^{33}$ This is in agreement with what was observed in Fig. 9a i.e. the rate-limiting steps were both the interparticle and intraparticle steps. ${ }^{28}$ Also, given the multilinearity of the plots, a three-stage adsorption process of BPA onto PPY/PANI was thus suggested: (i) the first steeper segment represented the external surface adsorption or interparticle diffusion, (ii) the second linear segment represented an adsorption stage or intraparticle diffusion and (iii) lastly, the equilibrium stage was described by the third linear segment. ${ }^{28,33}$

The slopes of the first two linear segments of the plots in Fig. 9b were also scrutinized to investigate the rates of reactions during the diffusion steps. Here it was observed that although both diffusion steps were rate limiting, the slopes of the first linear segments were steeper than the slopes of the second linear segments. This meant that the intraparticle diffusion step was slower than the interparticle diffusion step, in all the BPA concentrations investigated..$^{64}$

Meanwhile, the intraparticle diffusion constant $K_{\mathrm{p}}$ and the intercept $(C)$ were calculated from the second linear segment of the plots and were given in Table 2.

Adsorption isotherms of BPA onto PPY/PANI. The effect temperature had on the adsorption of BPA onto PPY/PANI was investigated in order to study the thermodynamics of the process. ${ }^{65}$ The isotherms data for the adsorption of BPA onto PPY/PANI is presented in Fig. 10.

It was seen that a significant increase in BPA uptake by PPY/ PANI was observed with increasing temperature, suggesting

Table 2 The interparticle and intraparticle diffusion model parameters for BPA adsorption onto PPY/PANI

Interparticle diffusion

model

Intraparticle diffusion model

\begin{tabular}{lllllll}
\hline & & & & \\
$C_{\mathrm{o}}\left(\mathrm{mg} \mathrm{L}^{-1}\right)$ & $k^{\prime}$ & $R^{2}$ & & $K_{\mathrm{p}}\left(\mathrm{mg} \mathrm{g}^{-1} \mathrm{~min}^{-0.5}\right)$ & $\begin{array}{l}C \\
\left(\mathrm{mg} \mathrm{g}^{-1}\right)\end{array}$ & $R^{2}$ \\
\hline 50 & 0.053 & 0.990 & 4.56 & 1.93 & 0.995 \\
75 & 0.030 & 0.991 & 7.68 & 0.09 & 0.996 \\
100 & 0.036 & 0.977 & 9.64 & 2.31 & 0.998
\end{tabular}

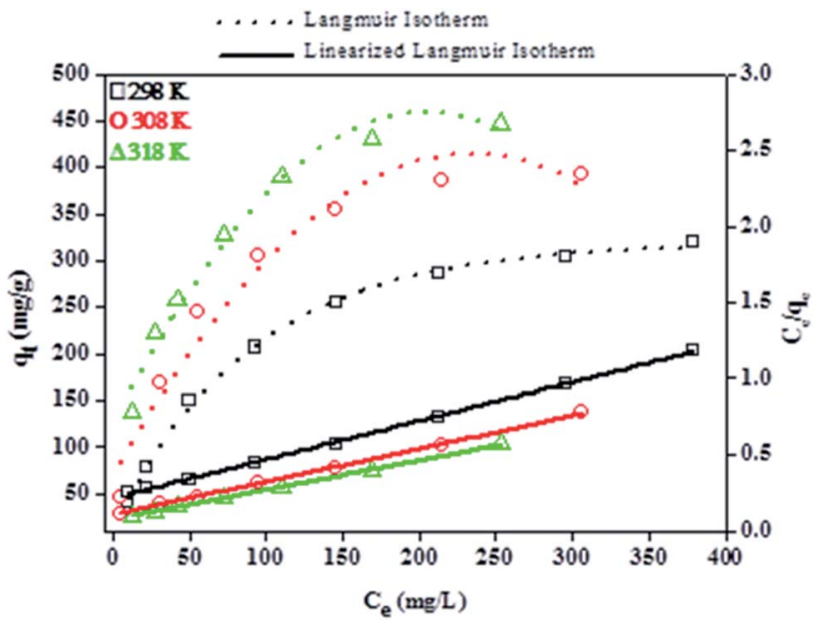

Fig. 10 Effect of solution temperature on the removal of BPA using PPY/PANI where the temperature is varied from 298 to $318 \mathrm{~K}$. Experimental conditions: $200 \mathrm{ml}$ of 50 ppm BPA and $100 \mathrm{mg}$ PPY/PANI.

that the adsorption of BPA onto PPY/PANI was endothermic. This was attributed to that, an increase in solution temperature resulted in increased mobility of the BPA molecules thus resulting in an increased driving force towards the adsorption sites of PPY/PANI.

Furthermore, the relationship between the amount of BPA adsorbed and the respective equilibrium concentration of BPA molecules in the liquid phase was assessed by subjecting the experimental isotherm data to the linearized forms of the Langmuir and Freundlich isotherm models. The linearized Langmuir isotherm, which is based on the monolayer adsorption on the adsorbent surface with identical adsorption sites, is represented by eqn (6):

$$
\frac{C_{\mathrm{e}}}{q_{\mathrm{e}}}=\frac{1}{q_{\mathrm{o}} b}
$$

where $q_{\mathrm{o}}\left(\mathrm{mg} \mathrm{g}^{-1}\right)$ is the maximum amount of BPA molecules per unit mass of adsorbent to form a complete monolayer on the adsorbent surface and $b\left(\mathrm{~L} \mathrm{mg}^{-1}\right)$ is the binding energy constant. ${ }^{66}$

Moreover, an essential characteristic of the Langmuir model, a dimensionless separation factor $\left(R_{\mathrm{L}}\right)$ used for defining the favourability of an adsorption process, was determined using eqn (7):

$$
R_{\mathrm{L}}=\frac{1}{\left(1+b C_{\mathrm{o}}\right)}
$$

where average values of $R_{\mathrm{L}}$ ranging between 0 and 1 for each of the initial BPA concentrations used specifies favorable adsorption. ${ }^{37}$ The Freundlich isotherm is an empirical model that is based on adsorption on a heterogeneous surface and is given by eqn (8):

$$
\ln q_{\mathrm{e}}=\ln K_{\mathrm{F}}+\frac{1}{n} \ln C_{\mathrm{e}}
$$

where $K_{\mathrm{F}}\left(\mathrm{mg} \mathrm{g}^{-1}\right)$ and $1 / n$ constants are related to the adsorption capacity and intensity of adsorption, respectively. ${ }^{37}$ 
Table 3 Langmuir and Freundlich adsorption parameters for BPA removal using PPY/PANI

\begin{tabular}{llllllllll}
\hline & & \multicolumn{3}{c}{ Langmuir isotherm } & & \multicolumn{3}{c}{ Freundlich isotherm } \\
$T(\mathrm{~K})$ & $q_{\mathrm{o}}\left(\mathrm{mg} \mathrm{g}^{-1}\right)$ & $b\left(\mathrm{~L} \mathrm{mg}^{-1}\right)$ & $R_{\mathrm{L}}$ & $R^{2}$ & & $K_{\mathrm{F}}\left(\mathrm{mg} \mathrm{g}^{-1}\right)$ & $1 / n$ & $R^{2}$ \\
\hline 298 & 400 & 0.012 & 0.27 & 0.998 & & 13.3 & 0.570 & 0.954 \\
308 & 455 & 0.021 & 0.16 & 0.999 & 23.4 & 0.536 & 0.948 \\
318 & 526 & 0.026 & 0.10 & 0.999 & 56.4 & 0.396 & 0.964
\end{tabular}

The Langmuir and Freundlich parameters were calculated from their respective linear plots, they were determined from the corresponding slopes and intercepts (Table 3). Higher correlation coefficients were observed when the adsorption data was fitted into the Langmuir model (Fig. 10) as opposed to when fitted into the Freundlich model (linear plot not shown). Moreover, the Langmuir maximum adsorption capacity, $q_{\mathrm{o}}$, corresponded adequately with the experimental adsorption capacities, $q_{\mathrm{e}}$, achieved for BPA adsorption onto PPY/PANI, for all the investigated temperatures. The values of $R_{\mathrm{L}}$ at different temperatures were found to be in the $0-1$ range, indicating that the adsorption process was favorable.

Thermodynamic parameters of adsorption. Thermodynamic considerations of an adsorption process are necessary to conclude whether the process is spontaneous or not. Gibb's free energy change, $\Delta G^{\circ}$, is the fundamental criterion of spontaneity. Reactions occur spontaneously at a given temperature if $\Delta G^{\circ}$ is a negative value. The thermodynamic parameters of Gibb's free energy change, $\Delta G^{\circ}$, enthalpy change, $\Delta H^{\circ}$, and entropy change, $\Delta S^{\circ}$, for the adsorption processes are calculated using the following equations:

$$
\begin{gathered}
\Delta G^{\circ}=-R T \ln K_{\mathrm{c}}=-R T \ln \left(\frac{m q_{\mathrm{e}}}{C_{\mathrm{e}}}\right) \\
\Delta G^{\circ}=\Delta H^{\circ}-T \Delta S^{\circ}
\end{gathered}
$$

where $R$ is a gas constant, $8.314 \mathrm{~J} \mathrm{~mol}^{-1}, m$ is the adsorbent mass $(\mathrm{g}), K_{\mathrm{c}}$ is the equilibrium constant of adsorption, $T$ (in Kelvin) is the temperature and finally, $q_{\mathrm{e}}$ and $C_{\mathrm{e}}$ are the equilibrium adsorption capacity and concentration of adsorbate at equilibrium, respectively. The thermodynamic parameters of $\Delta H^{\circ}$ and $\Delta S^{\circ}$ were obtained from the $\ln K_{\mathrm{c}}$ versus $1 / T$ plot (Fig. S6 $\dagger$ ). The Gibbs free energies $\left(\Delta G^{\circ}\right)$ were calculated from eqn (10) and the results are given in Table $\mathrm{S} 1 . \dagger$ The negative values of $\Delta G^{\circ}$ at $35^{\circ} \mathrm{C}$ and $45^{\circ} \mathrm{C}$ temperatures studied are due to the fact that the adsorption process is spontaneous. The negative value of $\Delta H^{\circ}$ suggests the exothermic nature of adsorption. The positive value of $\Delta S^{\circ}$ suggests increased randomness at the solid/solution interface during the adsorption of BPA onto PPY/ PANI-Fe ${ }^{0}$ composite.

Effect of $\mathbf{p H}$ on the adsorption behavior. The effect of solution $\mathrm{pH}$ on the adsorption of BPA onto PPY/PANI was investigated (Fig. S7a†). This was done because the solution $\mathrm{pH}$ influences both the chemistry of BPA and the surface charge of the adsorbent thereby governing the electrostatic interactions between the adsorbent and adsorbate. It was observed that the removal efficiency of BPA decreased slightly when the $\mathrm{pH}$ was decreased from 2 to 7 . At $\mathrm{pH}$ values higher than 7.5, a more significant decrease in removal efficiency was observed. The solution pH influences how BPA is adsorbed onto PPY/PANI in a similar way it influenced how BPA is adsorbed onto PPY (Fig. 4). Here, also, the observed behavior of BPA and PPY/PANI at different $\mathrm{pH}$ values was attributed to that the surface of PPY/ PANI becomes negatively charged at high $\mathrm{pH}$ values and it repels BPA derived monoanions and dianions that also form at high $\mathrm{pH}$ values. This was further supported by the point of zero charge (PZC) studies conducted on the adsorbent (Fig. S7b $\dagger$ ). It was found that at higher $\mathrm{pH}$ values (above the $\mathrm{pH}_{\mathrm{pzc}}$ values), the surface of PPY/PANI acquired a negative surface.

\section{Adsorption mechanism}

The adsorption mechanism between organic contaminants and carbon-based adsorbents usually involves electrostatic interactions. ${ }^{\mathbf{1 8 , 6 7}}$ Electrostatic interactions can either be repellent or attractive and this depends mostly on the charge densities of both the adsorbate and the adsorbent, which is influenced by the solution pH. In this work, we reported that the adsorption of BPA onto PPY/PANI was influenced by $\mathrm{pH}$. This was further demonstrated by studying the pzc of PPY/PANI. It was found that at high $\mathrm{pH}$ values the surface of the adsorbent accumulates a negative charge which is repellent to the negatively charged anions that BPA exist as at high $\mathrm{pH}$ values. Therefore, electrostatic interactions were part of the adsorption mechanism. The structure of BPA and that of both PPY and PANI consists of aromatic rings with delocalized $\pi$ electrons; therefore $\pi-\pi$ nonelectrostatic interactions were also part of the adsorption mechanism. It was also found that PPY/PANI is a relatively hydrophobic material at pH 6.2 (contact angle of $77.3^{\circ}$, Fig. S8 $\dagger$ ) and BPA is also hydrophobic. This means that the hydrophobic non-electrostatic interactions were also responsible for the adsorption of BPA onto PPY/PANI.

\section{Degradation of BPA}

Oxidative radicals, hydroxyl radicals, in particular, are the species responsible for the degradation of organic compounds in Fenton reactions. In order to investigate if $\mathrm{HO}^{\circ}$ were responsible for the degradation of BPA using $\mathrm{Fe}^{0}$-PPY/PANI and $\mathrm{H}_{2} \mathrm{O}_{2}$ in this work, BPA degradation experiments were carried out in the presence and absence of methanol and iodide ions. Methanol is capable of neutralizing hydroxyl radicals by scavenging them. The rate constant of the reaction between methanol and hydroxyl radicals is high (eqn (11)).

$$
\mathrm{CH}_{3} \mathrm{OH}+\mathrm{HO}^{\bullet} \rightarrow \mathrm{CH}_{3} \mathrm{OH}^{\bullet}+\mathrm{H}_{2} \mathrm{O},\left(k=9.7 \times 10^{8} \mathrm{M}^{-1} \mathrm{~s}^{-1}(11)\right.
$$

Iodide ions also scavenge hydroxyl radicals. Furthermore, iodide anions get adsorbed onto the catalyst easier than methanol. Therefore, when comparing methanol scavenging and iodide scavenging, it is possible to differentiate if the reaction occurs mostly on the material surface or in solution. ${ }^{\mathbf{1 1}}$ The rate constant for this reaction is defined as (eqn (12)): ${ }^{68}$ 


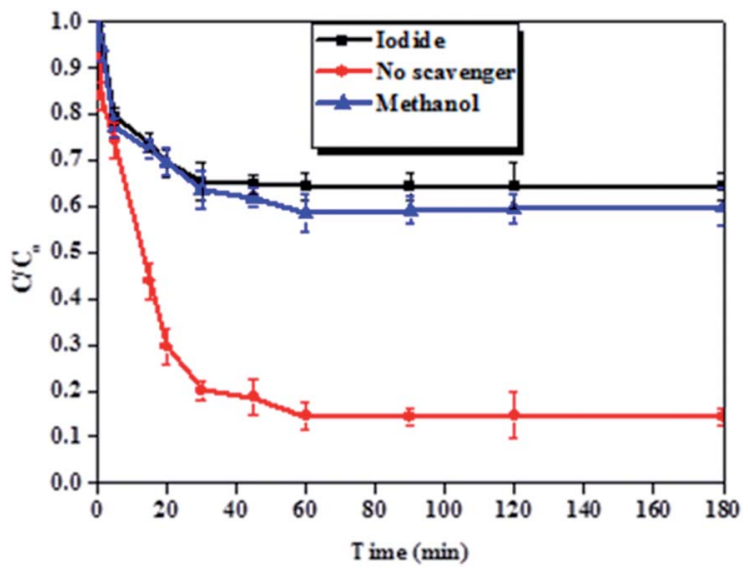

Fig. 11 Effect of methanol and potassium iodide on the removal of BPA. Experimental conditions: $200 \mathrm{ml}$ of $50 \mathrm{ppm} \mathrm{BPA}$ at pH 6 with $100 \mathrm{mg} \mathrm{Fe}{ }^{0}$-PPY/PANI and $5 \mathrm{mM} \mathrm{KI}$ or $350 \mathrm{mM}$ methanol.

$$
\mathrm{HO}^{\bullet}+\mathrm{I}^{-} \rightarrow \mathrm{I}^{\bullet}+\mathrm{OH}^{-},\left(k=1.02 \times 10^{10} \mathrm{M}^{-1} \mathrm{~s}^{-1}\right)
$$

It was detected that the experiment conducted without a scavenger yielded high BPA removal efficiency as compared to the experiments conducted in the presence of methanol and potassium iodide (Fig. 11). This indicated that hydroxyl radicals were responsible for the degradation of BPA in these experiments. Furthermore, it also observed that iodide ions attenuated the removal of BPA more than methanol, indicating that hydroxyl radicals were primarily surface-bound. ${ }^{69,70}$

In order to further investigate the mechanism at which BPA was removed, HPLC-MS analysis was conducted on aliquots sampled at $0 \mathrm{~min}, 30 \mathrm{~min}$, and $180 \mathrm{~min}$. This was from an experiment where BPA was degraded in the absence of any other additional contaminant or radical scavenger. It was observed that the BPA chromatogram consisted of only 1 peak at a retention time of $15.8 \mathrm{~min}$ and it was attributed to BPA (Fig. 12a).

The chromatogram of the aliquot sampled at $30 \mathrm{~min}$ had 3 peaks, the original BPA peak, and two others at 6.22 and $9.69 \mathrm{~min}$. The peak at $6.22 \mathrm{~min}$ was identified as 3-(4hydroxyphenyl)-3-methyl-2-oxobutanoic acid $(\mathrm{m} / \mathrm{z} 207$ negative mode) whereas the peak at 9.69 was identified as 4-ethynylphenol ( $\mathrm{m} / \mathrm{z} 118$ negative mode) (Fig. 12b). The intensity of BPA after 30 minutes was significantly smaller than that of BPA before the reaction commenced. This showed that BPA was
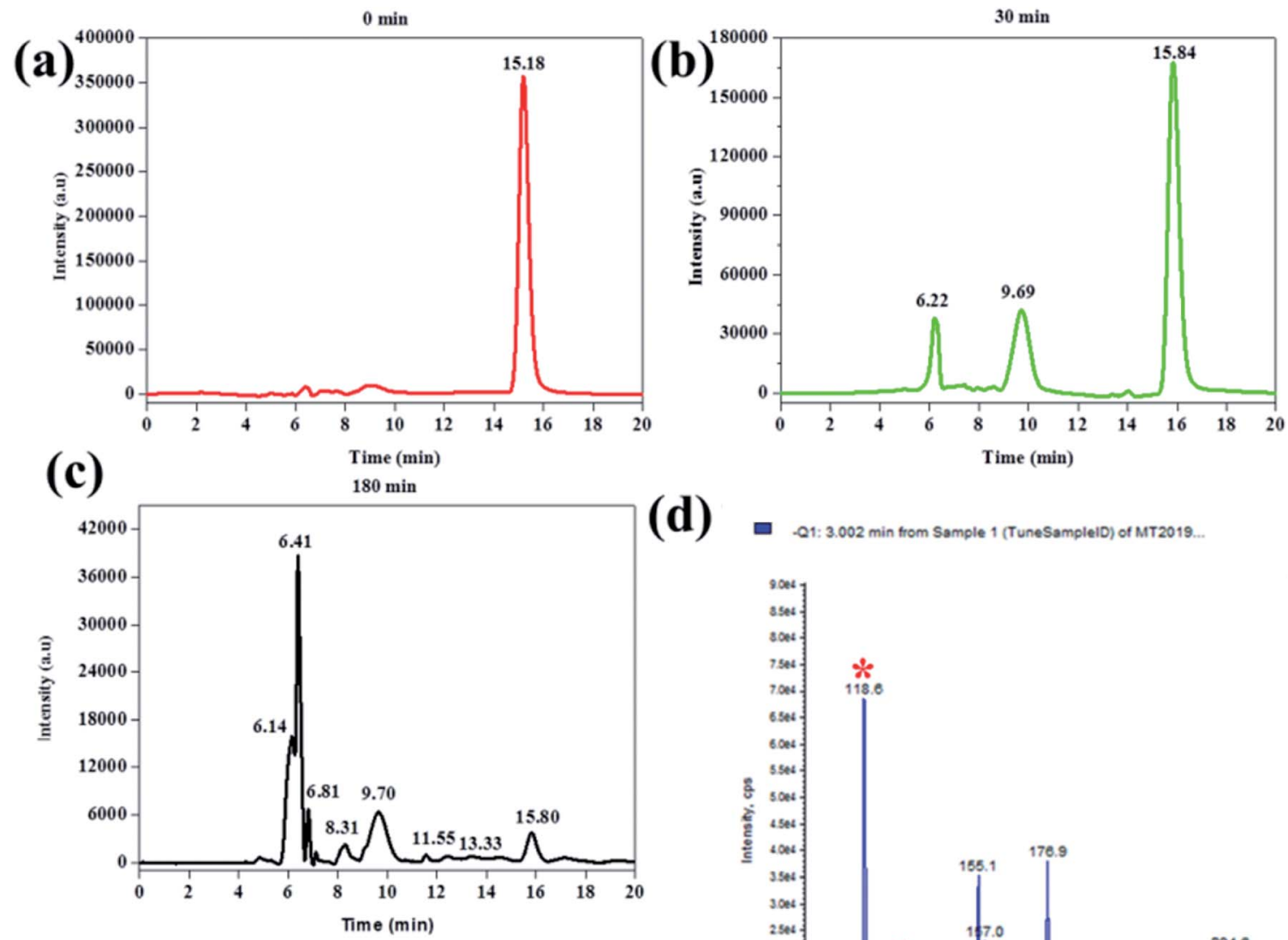

(d)

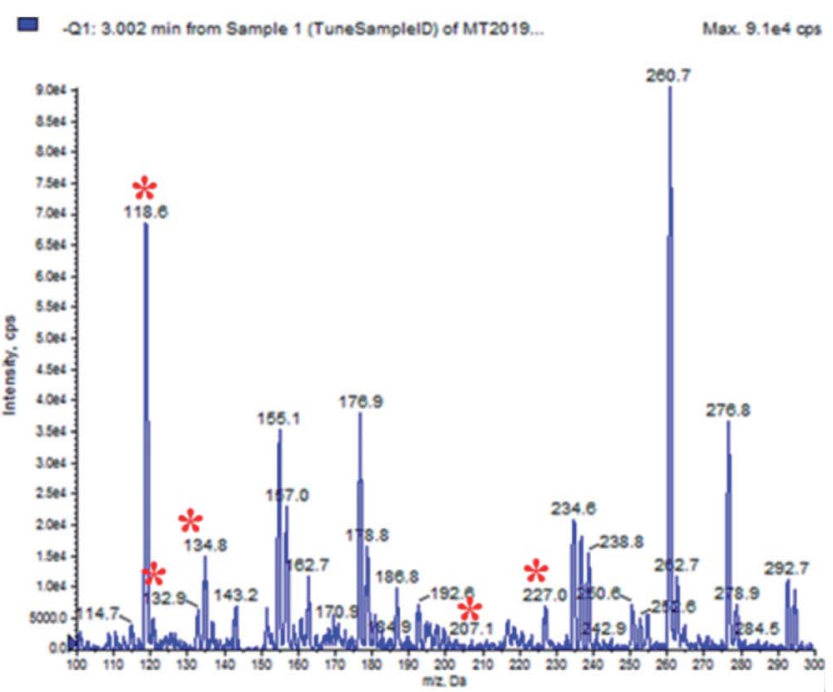

Fig. 12 Chromatograms of the aliquots sampled at (a) $0 \mathrm{~min}$, (b) $30 \mathrm{~min}$, (c) $180 \mathrm{~min}$ and (d) is the MS spectrum of the aliquot sample at $180 \mathrm{~min}$. Experimental conditions: $200 \mathrm{ml}$ of 50 ppm BPA at pH 6 with 100 mg Fe ${ }^{0}$-PPY/PANI. 
removed from the sample and that smaller compounds were formed as a direct result of its degradation.

The chromatogram of the aliquot sampled at 180 min consisted of several peaks, including the 3 compounds identified above. The other compounds at 13.33 and $8.31 \mathrm{~min}$ were identified as 1-(-4-hydroxyphenyl)ethanone $(\mathrm{m} / \mathrm{z} 135$ negative mode and 4-(prop-1-en-2-yl)phenol $(\mathrm{m} / \mathrm{z}$ 133), respectively (Fig. 12c). Furthermore, the mass spectrum of the aliquot sampled at $180 \mathrm{~min}$ was recorded (Fig. 11d). Here, the peaks representing peaks that were identified on the corresponding chromatogram (Fig. 11c) were observed and identified with asterisks on Fig. 11d. Unfortunately, the rest of the peaks, both on the chromatogram (Fig. 12c) and mass spectrum (Fig. 12d) were not identified. Nevertheless, it is clear that BPA was degraded and other compounds were formed as a result. The degradation by-products that were identified in this work were previously identified in other reports, were BPA was degraded using different techniques like the one reported in this work. For instance, in one article they reported the ultrasonic degradation of BPA and they identified compounds that were identified in this work. ${ }^{71}$ In another study by Fukahori et al. their BPA photodecomposition experiments also yielded compounds that were identified in this work. ${ }^{72}$ These reports also attributed the degradation of BPA and formation of these intermediates to the action of hydroxyl radicals, further supporting the postulation made in this report. Furthermore, it was found from TOC measurements that the amount of organic carbon had been reduced by $57 \%$, showing that some of the BPA had been turned into possibly $\mathrm{CO}_{2}$. The possible degradation mechanism from looking at the paper holistically is as follows. The first step is that BPA gets adsorbed onto $\mathrm{Fe}^{0}$-PPY/PANI (see Fig. 5a, where it was shown that $\mathrm{Fe}^{0}$-PPY/PANI removed more than $50 \%$ of BPA by absorption). This is crucial as in advanced oxidation processes adsorbed pollutant molecules get degraded quicker than the pollutant molecules in solution. In the presence of $\mathrm{H}_{2} \mathrm{O}_{2}$ in an acidic medium, $\mathrm{Fe}^{0}$ immobilized on PPY/PANY was oxidized to $\mathrm{Fe}^{2+}$ on the surface of $\mathrm{Fe}^{0}$-PPY/PANI (eqn (13)). This is represented as $\mathrm{Fe}^{2+}-\mathrm{PPY} / \mathrm{PANI}$. Further evidence for that $\mathrm{Fe}^{0}$ was oxidized to $\mathrm{Fe}^{2+}$ on the surface of the composite was deduced from that iodide ions reduced the removal efficiency of BPA better than methanol.

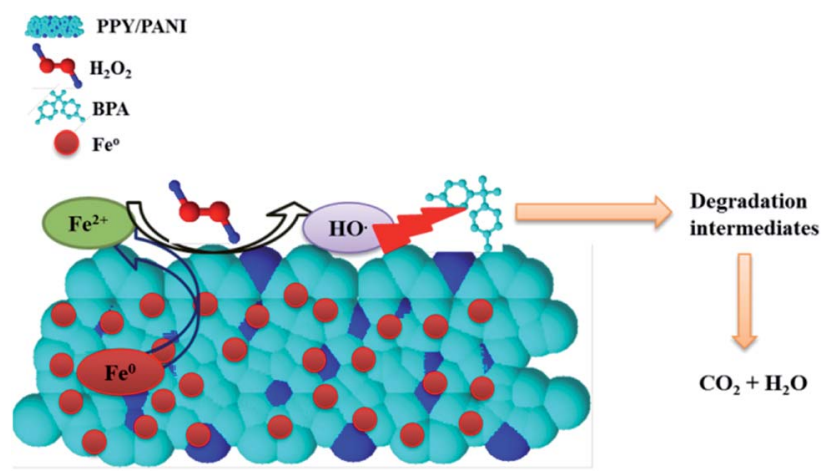

Fig. 13 Advanced Fenton reaction mechanism for the degradation of BPA using $\mathrm{Fe}^{0}$-PPY/PANI.

$$
\mathrm{Fe}^{0}-\mathrm{PPY} / \mathrm{PANI}+\mathrm{H}_{2} \mathrm{O}_{2} \rightarrow \mathrm{Fe}^{2+}-\mathrm{PPY} / \mathrm{PANI}+2 \mathrm{OH}^{-}
$$

It was also shown by the use of methanol and potassium iodide as scavengers that hydroxyl radicals were responsible for the degradation of BPA. Therefore the next step after the oxidation of $\mathrm{Fe}^{0}$-surface to $\mathrm{Fe}^{2+}$-surface is the reaction between iron species and $\mathrm{H}_{2} \mathrm{O}_{2}$ to form the hydroxyl radicals. From here on, a series of chemical reactions occurred until BPA was degraded into smaller products and subsequently $\mathrm{CO}_{2}$. Some of the chemical reactions that occurred are represented by the following chemical equations. The general mechanism is conceptualized graphically in Fig. 13.

$$
\begin{gathered}
\mathrm{Fe}^{2+} \text {-surface }+\mathrm{H}_{2} \mathrm{O}_{2} \rightarrow \mathrm{Fe}^{3+} \text {-surface }+2 \mathrm{HO}^{\circ} \\
\mathrm{Fe}^{2+} \text {-surface }+\mathrm{H}_{2} \mathrm{O}_{2} \rightarrow \mathrm{Fe}^{3+} \text {-surface }+\mathrm{HO}^{-}+\mathrm{HO}^{\circ} \\
\mathrm{HO}^{\bullet}+\text { BPA } \rightarrow \text { degradation by-products } \rightarrow \mathrm{CO}_{2}+\mathrm{H}_{2} \mathrm{O}
\end{gathered}
$$

\section{Conclusions}

A series of polymeric and/or iron zero-based materials were synthesized and used as adsorbents and as Fenton catalysts along with $\mathrm{H}_{2} \mathrm{O}_{2}$ towards the removal of BPA in water. It was seen that polymeric materials were more potent at adsorption whereas materials that contained $\mathrm{Fe}^{0}$ were more active at Fenton reactions. The presence of other organic contaminants reduced the BPA in both adsorption and Fenton reactions, whereas increasing the ionic strength of the solution favored the removal of BPA in Fenton reactions. In these experiments, it was seen that PPY/PANI was the most potent adsorbent, while $\mathrm{Fe}^{0}$-PPY/PANI was found to be the best Fenton catalyst. Unfortunately, the adsorbents and Fenton catalysts were not as effective for removing BPA in the presence of sewage-water, even the TOC removal efficiency was low but it was shown that at the mass of catalyst or adsorbent and $\mathrm{H}_{2} \mathrm{O}_{2}$ concentration, the efficiencies could be increased. The adsorption of BPA onto PPY/PANI was characterized by the pseudo-second-order kinetics model whereas $\mathrm{Fe}^{0}$-PPY/PANI activated $\mathrm{H}_{2} \mathrm{O}_{2}$ to form hydroxyl radicals that were then responsible for the removal of BPA. This report demonstrates the synthesis of potent adsorbent and Fenton catalyst for the removal of BPA. The synthesis procedure is a relatively easy one and the materials are relatively eco-friendly.

\section{Conflicts of interest}

The authors declare that there is no conflict of interest.

\section{Acknowledgements}

The authors would like to express their gratitude to the Council of Scientific and Industrial Research for providing the facilities and resources under project number HP1312P. The University of Witwatersrand, the Microanalysis and Microscopy (MMU) in particular is acknowledged for their assistance with 
characterization. Prof. Ndinteh from the University of Johannesburg assisted with TOC measurements; his contribution is appreciated by the authors.

\section{Notes and references}

1 C. A. Staples, P. B. Dom, G. M. Klecka, T. O. Sandra and L. R. Harris, Chemosphere, 1998, 36, 2149-2173.

2 C. D. Kassotis, D. A. Alvarez, J. A. Taylor, S. Frederick, S. C. Nagel and D. E. Tillitt, Sci. Total Environ., 2015, 524525, 384-393.

3 H. Fukazawa, K. Hoshino, T. Shiozawa, H. Matsushita and Y. Terao, Chemosphere, 2001, 44, 973-979.

4 G. Mezohegyi, B. Erjavec, R. Kaplan and A. Pintar, Ind. Eng. Chem. Res., 2013, 52, 9301-9307.

5 M. Boas, U. Feldt-Rasmussen and K. M. Main, Mol. Cell. Endocrinol., 2012, 355, 240-248.

6 J. A. Rogers, L. Metz and V. W. Yong, Mol. Immunol., 2013, 53, 421-430.

7 N. Casajuana and S. Lacorte, Chromatographia, 2003, 57, 649-655.

8 J. Muncke, J. Steroid Biochem. Mol. Biol., 2011, 127, 118-127. 9 D.-K. Li, Z. ZhiJun, M. Maohua, H. Yonghua, W. JinTao, J. Ferber, L. J. Herrinton, E. Gao and W. Yuan, Fertil. Steril., 2011, 95, 625-630.

10 T. Paulose, L. Speroni, C. Sonnenschein and A. M. Soto, Reprod. Toxicol., 2015, 54, 58-65.

11 K. L. Howdeshell, P. H. Peterman, B. M. Judy, J. A. Taylor, C. E. Orazio, R. L. Ruhlen, F. S. vom Saal and W. V. Welshons, Environ. Health Perspect., 2003, 111, 11801187.

12 T. A. Ternes, J. Stuber, N. Herrmann, D. Mcdowell, A. Ried, M. Kampmann and B. Teiser, Water Res., 2003, 37, 19761982.

13 J. Matos, J. Laine and J. Herrmann, Appl. Catal. B Environ., 1998, 18, 281-291.

14 L. Hlekelele, P. J. Franklyn, F. Dziike and S. H. Durbach, New J. Chem., 2018, 42, 4531-4542.

15 M. Mezcua, M. A. Martínez-Uroz, M. M. Gómez-Ramos, M. J. Gómez, J. M. Navas and A. R. Fernández-Alba, Talanta, 2012, 100, 90-106.

16 E. Erdem, N. Karapinar and R. Donat, J. Colloid Interface Sci., 2004, 280, 309-314.

17 V. K. Gupta and I. Ali, Water Res., 2001, 35, 33-40.

18 C. Moreno-Castilla, Carbon, 2004, 42, 83-94.

19 V. C. Srivastava, M. M. Swamy, I. D. Mall, B. Prasad and I. M. Mishra, Colloids Surf., A, 2006, 272, 89-104.

20 A. Dabrowski, P. Podkosccielny, Z. Hubicki and M. Barczak, Chemotherapy, 2005, 58, 1049-1070.

21 L. Hao, H. Song, L. Zhang, X. Wan, Y. Tang and Y. Lv, J. Colloid Interface Sci., 2012, 369, 381-387.

22 Y. Wang, H. Sun, X. Duan, H. M. Ang, M. O. Tadé and S. Wang, Appl. Catal., B, 2015, 172-173, 73-81.

23 D. O. Carroll, B. Sleep, M. Krol, H. Boparai and C. Kocur, Adv. Water Resour., 2013, 51, 104-122.

24 F. V. Avelar Dutra, B. C. Pires, T. A. Nascimento, V. Mano and K. B. Borges, RSC Adv., 2017, 7, 12639-12649.
25 F. V. A. Dutra, B. C. Pires, T. A. Nascimento and K. B. Borges, J. Environ. Manage., 2018, 221, 28-37.

26 T. A. Do Nascimento, F. V. A. Dutra, B. C. Pires and K. B. Borges, New J. Chem., 2018, 42, 7030-7042.

27 B. C. Pires, F. V. A. Dutra, T. A. Nascimento and K. B. Borges, React. Funct. Polym., 2017, 113, 40-49.

28 H. Liu, H. Zhang and H. Yang, Chin. J. Catal., 2014, 35, 6677.

29 A. T. Kuvarega, Photocatalytic performance of nitrogenplatinum group metal co-doped $\mathrm{TiO}_{2}$ supported on carbon nanotubes for visible-light degradation of organic pollutants in water, University of Johannesburg, 2012.

30 L. Hlekelele, P. J. Franklyn, P. K. Tripathi and S. H. Durbach, RSC Adv., 2016, 6, 76773-76779.

31 W. Liu, H. Zhang, B. Cao, K. Lin and J. Gan, Water Res., 2010, 45, 1872-1878.

32 P. Bautista, A. F. Mohedano, J. A. Casas, J. A. Zazo and J. J. Rodriguez, J. Chem. Technol. Biotechnol., 2008, 83, 1323-1338.

33 Y. Ohko, A. Isao, N. Chisa, T. Tetsu, Y. Tsuyoshi, N. Tetsuto, F. Yoshinobu, Y. Kubota and A. Fujishima, Environ. Sci. Technol., 2001, 35, 2365-2368.

34 F. Dziike, P. J. Franklyn, S. H. Durbach, M. Maubane and L. Hlekelele, Mater. Res. Bull., 2018, 104, 220-226.

35 C. Liao, Z. D. Wei, S. G. Chen, L. Li, M. B. Ji, Y. Tan and M. J. Liao, J. Phys. Chem. C, 2009, 113, 5705-5710.

36 R. Ahmad and R. Kumar, J. Chem. Eng. Data, 2010, 55, 34893493.

37 K. Zebedius, M. Bhaumik, S. Songwane, M. S. Onyango and A. Maity, Chem. Eng. J., 2013, 222, 186-197.

38 J. Li, J. Feng and W. Yan, Appl. Surf. Sci., 2013, 279, 400-408.

39 M. Bhaumik, R. I. Mccrindle and A. Maity, Chem. Eng. J., 2015, 260, 716-729.

40 R. V. Kumar, A. K. Basumatary, A. K. Ghoshal and G. Pugazhenthi, RSC Adv., 2015, 5, 6246-6254.

41 L. Hlekelele, P. J. Franklyn, F. Dziike and S. H. Durbach, New J. Chem., 2018, 42, 1902-1912.

42 Y. Ma, S. Jiang, G. Jian, H. Tao, L. Yu and X. Wang, Energy Environ. Sci., 2009, 2, 224-229.

43 X. Zhang, J. Zhang, W. Song and Z. Liu, J. Mater. Sci. Mater. Electron., 2006, 110, 1158-1165.

44 T. Wu and Y. Lin, Polymer, 2006, 47, 3576-3582.

45 Y. Hwang, D. Kim and H. Shin, J. Hazard. Mater., 2011, 185, 1513-1521.

46 A. Rahy, T. Rguig, S. June, C. E. Bunker and D. Joo, Synth. Met., 2011, 161, 280-284.

47 M. A. Chougule, S. Sen and V. B. Patil, J. Appl. Polym. Sci., 2012, 125, 542-547.

48 J. Heo, J. R. V. Flora, N. Her, Y. Park, J. Cho, A. Son and Y. Yoon, Sep. Purif. Technol., 2012, 90, 39-52.

49 S. Li, Y. Gong, Y. Yang, C. He, L. Hu, L. Zhu and L. Sun, Chem. Eng. J., 2015, 260, 231-239.

50 A. Shimizu, M. Tokumura, K. Nakajima and Y. Kawase, J. Hazard. Mater., 2012, 201-202, 60-67.

51 L. Gomathi Devi, S. Girish Kumar, K. Mohan Reddy and C. Munikrishnappa, J. Hazard. Mater., 2009, 164, 459-467.

52 E. Neyens and J. Baeyens, J. Hazard. Mater., 2003, 98, 33-50. 
53 P. V. Nidheesh and R. Gandhimathi, Desalination, 2012, 299, 1-15.

54 F. Lücking, H. Köser, M. Jank and A. Ritter, Water Res., 1998, 32, 2607-2614.

55 L. Joseph, J. Heo, Y. G. Park, J. R. V. Flora and Y. Yoon, Desalination, 2011, 281, 68-74.

56 J. J. Pignatello, S. Kwon and Y. Lu, Environ. Sci. Technol., 2006, 40, 7757-7763.

57 J. E. Kilduff and A. Wigton, Environ. Sci. Technol., 1999, 33, 250-256.

58 I. Bautista-Toledo, M. A. Ferro-García, J. Rivera-Utrilla, C. Moreno-Castilla and F. J. V. Fernández, Environ. Sci. Technol., 2005, 39, 6246-6250.

59 G. Liu, J. Ma, X. Li and Q. Qin, J. Hazard. Mater., 2009, 164, 1275-1280.

60 W. Ma, N. Wang, Y. Du, T. Tong, L. Zhang, K. Y. Andrew Lin and X. Han, Chem. Eng. J., 2019, 356, 1022-1031.

61 Y. Feng, P. Lee, D. Wu and K. Shih, Environ. Sci. Technol., 2017, 51, 2312-2320.
62 A. Enakpodia and E. Iyayi, J. Taiwan Inst. Chem. Eng., 2013, 44, 566-576.

63 E. I. Unuabonah, G. U. Adie, L. O. Onah and O. G. Adeyemi, Chem. Eng. J., 2009, 155, 567-579.

64 H. K. Boparai, M. Joseph and D. M. O. Carroll, J. Hazard. Mater., 2011, 186, 458-465.

65 Y. S. Al-Degs, M. I. El-Barghouthi, A. H. El-Sheikh and G. M. Walker, Dyes Pigm., 2008, 77, 16-23.

66 I. Demiral, T. Fatma and B. Karabacako, Chem. Eng. J., 2008, 144, 188-196.

67 W. Chen, L. Duan, D. Zhu, W. E. I. Chen and L. I. N. Duan, Environ. Sci. Technol., 2007, 41, 8295-8300.

68 J. K. Thomas, Trans. Faraday Soc., 1965, 61, 702-707.

69 Z. Wan and J. Wang, J. Hazard. Mater., 2017, 324, 653-664.

70 W. Raza, S. M. Faisal, M. Owais, D. Bahnemann and M. Muneer, RSC Adv., 2016, 6, 78335-78350.

71 R. A. Torres, C. Pétrier, E. Combet, M. Carrier and C. Pulgarin, Ultrason. Sonochem., 2008, 15, 605-611.

72 S. Fukahori, H. Ichiura, T. Kitaoka and H. Tanaka, Appl. Catal. B Environ., 2003, 46, 453-462. 